\title{
Função paterna, fratria e violência: sobre a constituição do socius na psicanálise freudiana
}

\author{
Leônia Cavalcante Teixeira ${ }^{1}$
}

\begin{abstract}
Resumo
As reflexões que se seguem objetivam elaborar a contribuição freudiana em relação à constituição do sujeito e do socius. Para tanto, iniciou-se com a problematização do artigo Totem e tabu, ressaltando nele as funções paterna e fraterna como fundamentais à constituição subjetiva operada na trama social. Em um segundo momento, a fratria foi destacada como espaço ético no qual as vicissitudes dos laços sociais se efetuam. A ambivalência Eros-Tanatos foi destacada, especialmente pelo caráter de um dualismo não simplista. Tal discussão abordou os riscos do exercício não tão silencioso da pulsão de morte nas configurações societárias contemporâneas.

Palavras-chave: Psicanálise; Sociabilidade; Fratria; Ética; Cultura.
\end{abstract}

\section{Fatherhood function, phratry and violence: on the constitution of socius in freudian psychoanalysis}

\begin{abstract}
The following reflective thoughts aim at elaborating a freudian contribution regarding the constitution of the subject and of the society. Beginning with the problematic issues of the article Totem and Taboo, the fatherhood and fraternal function were highlighted as fundamental to the subjective constitution, which operates in the social tissue. In the second part, the phratry was highlighted as the ethical space in which the alternation of the social ties is affected. The ambivalent Eros-Tanatos was also highlighted, especially by the nature of a dualism, which is not simplistic. The discussion deals with the risks of using not so silent instinct of death in the configuration of contemporary members of society.

Keywords: Psychoanalysis; Sociability; Phratry; Ethics; Culture.
\end{abstract}

Tal discussão abordou os riscos do exercício não tão silencioso da pulsão de morte nas configurações societárias contemporâneas.

\section{Introdução}

Seguir pistas sobre a questão da gênese da cultura e da violência na obra freudiana parece tornar sensível o lugar de importância do texto Totem e Tabu (Freud, 1913), ressaltando que apesar deste abordar o advento do social e das instituições, não merece ser pensado somente por esse viés. A redução de sentido da leitura do citado artigo parece não fazer justiça a Freud, já que ele delineia a gênese do sujeito, enfatizando os impasses e avanços com os quais se defrontava quanto à relação entre civilização e sexualidade, núcleo da teoria das neuroses. Nessa perspectiva, Assoun (1993) afirma que a experiência da neurose aguça o interesse freudiano pela cultura, funcionando como um verdadeiro operador de leitura do social.
Totem e Tabu (Freud, 1913) merece ser, de fato, lido como texto de psicanálise, inserindo-se na obra freudiana em um movimento de elaboração teórica que se inicia com A Sexualidade na Etiologia das Neuroses (Freud, 1898). Nesse percurso de construção clínica e conceitual, situam-se também os textos freudianos: Os Três Ensaios para uma Teoria da Sexualidade (1905), Comportamentos Obsessivos e Práticas Religiosas (1907), Moral Sexual Civilizada e Doença Nervosa Moderna (1908), Notas sobre um Caso de Neurose Obsessiva (1909), Uma Recordação de Infância de Leonardo da Vinci (1910), O Moisés de Michelangelo (1913), Psicologia das Massas e Análise do Eu (1921), O Futuro de uma Ilusão (1927), O Mal-estar na Civilização (1930) e Por que a Guerra? (1933).

O referido texto freudiano de 1913 apresenta as noções - tão caras para a psicanálise - de desejo

${ }^{1}$ Endereço para correspondência:

Av. Santos Dumont, 7007-902 - Papicu - Fortaleza-CE - 60150-160

E-mail:leoniat@,unifor.br 
incestuoso e parricídio, ambivalência afetiva, culpabilidade e consciência moral, sendo essas articuladas com base na confluência das contribuições da antropologia, da mitologia, da ciência da religião e, fundamentalmente, da clínica psicanalítica. A ficção freudiana, mesmo se mostrando carente de presteza antropológica - aliás, o próprio Freud lembra, em Moisés e o Monoteísmo: três ensaios (1939), que não é desse campo que fala! -, faz emergir a história humana como trágica, a partir do sentimento de amor e ódio em guerra contínua. Indicamos que o ato fundador do sujeito e do social afirma-se por sua violência que, segundo Jerusalinsky (1996, p. 9), pode ser entendida como "agressivização primordial". Enfocamo-lo como ato de transgressão, inscrevendo o sujeito como marcado pelo desamparo e pela estranheza com os quais o Outro lhe confronta.

Intencionamos, neste artigo, discutir temáticas relevantes à constituição do sujeito e da coletividade a partir das elaborações de Freud em Totem e Tabu (1913), que são desenvolvidas e complexificadas em outros momentos de sua obra.

\section{Renúncia pulsional e fraternidade}

Freud (1913) lança sua hipótese sobre um momento inaugural da cultura a partir da construção do que denomina mito cientifico, tomando como ponto de sustentação a etnologia. Segundo Mezan (1990, p. 319), essa via de análise "não pode ser dissociada de sua finalidade essencial, de natureza propriamente psicanalítica". No texto Totem e Tabu (1913), o fundador da Psicanálise põe em evidência duas práticas estranhas do ponto de vista utilitarista: o totemismo e o tabu. Tais práticas erguem-se sobre um solo de irracionalidade, baseada no qual toda a possibilidade de existência da sociedade pode ser considerada. É inegável a importância de tal reconhecimento, pois o caráter de uma teoria sobre a construção do sujeito e do socius afirmada no postulado do primado do simbólico rompe com explicações que se apóiam em visões utilitaristas.

Em Totem e Tabu (1913), Freud ergue o tabu do incesto como pedra angular da sociedade, constituindo esse temor e seu derivado - a exogamia - marcos da passagem do estado de natureza ao de cultura, ou seja, do ingresso do homem anárquico na ordem social. Tal passagem se firma pelo pacto fundador entre os irmãos, o que significa dizer que esse se faz pela fratria. $\mathrm{O}$ alvo primordial desse ato fundador consiste na obstacularização da onipotência característica daquele que antes ocupava o lugar de chefe, sendo destituído ao ser assassinado pelos seus súditos, passando a ocupar um lugar de Pai mítico.
É com base na impotência dos súditos ante a onipotência absoluta do chefe - detentor de todas as terras e mulheres - que eles se unem no planejamento e efetivação de um crime, visando ocupar tal lugar de privilégio. Porém, o que sucede ao ato de assassinato é a afirmação da impossibilidade desse lugar vir a ser ocupado por alguém em particular. A busca pela onipotência, paradoxalmente, coloca-a como necessariamente impossível, propiciando a gênese de uma comunidade de iguais: os irmãos se identificam na culpa e no arrependimento pelo assassinato, como escreve Freud (1913).

O que leva à cultura, portanto, é o confronto entre a onipotência do chefe e a impotência dos súditos e, posteriormente, o estabelecimento da Lei primeira: ninguém mais pode tudo, somente a partir das leis, agora fundamentais, é que os sujeitos podem se situar. O pai primevo freudiano passa a sustentar o estatuto metafórico de nó instaurador da cultura e da civilização, sendo pelo crime primordial que a Lei é inaugurada e engendrada, mediante o reconhecimento dos irmãos entre si, tomando por base os sentimentos advindos da força libidinal, de culpabilidade e de arrependimento. Em relação à temática da violência, a postulação freudiana explicativa da gênese do social merece ser destacada, pois em tal empreendimento teórico encontra-se o fundamento da rede social.

A organização coletiva é pensada valendo-se da Lei do Pai e da fraternidade, que se torna necessária entre os irmãos. A construção de um reino baseado na abstinência do poder absoluto sobre mulheres e terras constitui fundamento para a evitação da guerra e divisão do grupo. Portanto, o laço libidinal que é abordado em Totem e Tabu (1913) e, posteriormente em Psicologia das Massas e Análise do Eu (1921), enfoca a relação entre pai e filhos e entre irmãos. Ambas as modalidades de sustentação da rede social não são firmadas sobre a abolição do ódio, como modalidade de violência. Muito pelo contrário, ambas se sustentam na concretização de uma rede social firmada na ambivalência libidinal.

É a partir da tese de um ato inaugural de violência que o complexo edípico pode ser articulado. Como já proferimos, é um mesmo ato que funda o sujeito e a cultura, sendo esta efetivada por uma comunidade de iguais e não por um núcleo centralizado de poder. É o ódio compartilhado e o desejo de matar, juntamente com a culpabilidade e o arrependimento, que geram a irmandade como possibilidade de alguma coesão grupal. Kaufmann (1974, p. 177) enfatiza que "o caráter coletivo do assassinato o distingue da passagem 
ao ato individual", garantindo a comunidade social e não mais um ato de totalitarismo do chefe da horda.

No momento da escrita de Totem e Tabu (1913), Freud ainda não havia forjado os conceitos de superego e de pulsão de morte, embora estes já se situem virtualmente no seu arcabouço teórico, tanto na tão acentuada ambivalência e culpabilidade - ambas inconscientes - que ele reconhece nos primitivos e em nossas fantasias neuróticas, bem como na construção do material clínico do paradigmático Homem dos Ratos (1909), no qual é aflorado o ódio em sua potência de força amedrontadora. Quanto ao superego, herdeiro do Complexo de Édipo pela introjeção da proibição do incesto, é dele que deriva o mais elevado da vida ética

A entrada na cultura e na sociedade é marcada pelo signo da castração e da falta, sendo o programa de ser feliz irrealizável. Isso não quer dizer que a cultura só possa ser dita pelas terríveis restrições que traz à sexualidade e à agressividade. Ela impõe, certamente, suas rigorosas condições, que são o que possibilitam a vida coletiva e, concomitantemente, a construção do sujeito. A convivência permite vínculos, apoio, reforço e, principalmente, o amor e o trabalho. A cultura é fruto de Eros, do desejo de coesão, de união, de ligação, de constituir unidades cada vez maiores.

A psicanálise não é inimiga da cultura, entretanto reconhece o seu necessário caráter paradoxal como provedora do sujeito pelos vínculos que promove e como maior arma contra ele próprio pela possibilidade sempre presente de ruína dos esforços humanos para a coesão. Esse caráter de paradoxo inscreve-a fora das tentativas supostamente não conflituosas das retóricas ocidentais modernas. Essas tentativas ora se sustentam sobre a reconciliação plena com um estado originário tomado como ideal e perdido, ora sobre falência da cultura ou ascensão de ilusões totalitárias.

Em Psicologia das Massas e Análise do Eu (1921), Freud investiga os mecanismos e dispositivos do funcionamento do social, discutindo mesmo a vida das instituições ao consagrar ricas elaborações sobre a constituição dos grupos ligados por um ideal comum e à organização das massas conduzidas por um líder incontestado. A identificação constitui um dos mecanismos que promovem o vínculo social. Freud dedica ao referido processo uma interessante análise com base na relevância que atribui às massas, já que essas revelam as condições nucleares da sociabilidade, constituintes do sujeito e do socius em um mesmo movimento.

O sujeito se impõe como membro de um coletivo, sendo configurado valendo-se de suas regras e seus modos de geração subjetiva. Se o vislumbrarmos do ângulo de sua constituição fantasmática, temos que priorizar que, na maioria dos casos, os desejos do sujeito em sua relação à alteridade não se dispõem à conformidade exigida para que ele faça parte de uma massa.

A análise da participação do sujeito na coletividade nos permite apreender algo de essencial em relação ao laço social, mesmo que aí sejam enfocados, prioritariamente, fenômenos associativos fusionais, ora temporários, ora permanentes. A inserção do sujeito em um grupo possibilita que algo do porquê e do como viver junto aos outros possa ser iluminado. Desde que os sujeitos sejam envolvidos pelos poderes de um aglomerado tal qual uma massa, começa a operar um mecanismo que muito chama a atenção do fundador da psicanálise: a desindividualização. $\mathrm{O}$ pertencimento a um coletivo, tal qual descrito por Freud em Psicologia das Massas e Análise do Eu (1921), pressupõe que os mecanismos da identificação, da sugestão e do contágio recíproco operem no sentido do desinvestimento em um processo de singularização, já que promovem uma espécie de uniformização, às vezes, inacreditavelmente forte.

É reconhecendo a importância da identificação como um dos dispositivos que promovem o vínculo social que Freud (1921) sublinha os estados de amor, de hipnose e de multidão. Tais estados levam os indivíduos a agirem, muitas vezes, de modo irracional, intolerante, com raciocínio ilógico e degradação moral. Não se trata propriamente de um texto de antropologia, de sociologia, tampouco de psicologia social. O foco da análise freudiana, no texto supracitado, recai no coletivo pensado pela lógica do sintoma.

Para a aliança inaugural do social, faz-se necessária uma transformação do lugar dos filhos que, agora, expõem-se como irmãos, instaurando uma relação com os primeiros objetos de amor que não se faz mais no registro do imediato. É dessa maneira que é possível se pensar na instalação de uma distância mínima em relação aos objetos primeiros de amor. $\mathrm{Na}$ verdade, a prevalência do amor só é possível pela abstinência ao desfruto ilimitado dos objetos de prazer, sendo esse o preço que os irmãos têm que pagar para que uma formação social, que lhes assegure a vida, seja instalada. É fundamental, portanto, que os sujeitos deixem de se enclausurar na posição de filhos de um Pai todo-poderoso, assumindo-se como irmãos.

Ressaltamos que é importante marcar o caráter fundamental de o amor, para Freud, constituir o princípio de formação das associações humanas. É graças a Eros e seu poder unificador que os grupos podem ser pensados. 
Eros resiste à morte, insiste e retorna eternamente. Embora viver constitua um mal-estar mortal, o humano não tem vocação para a morte, sempre podendo ressurgir das cinzas. Freud indica ser Eros a mais poderosa força motriz do gênero humano, sendo ela que suporta a resistência à destruição e a valorização de Ananké (necessidade) como sua eterna incentivadora. Escreve Freud (1930, p. 170-172):

\section{os homens adquiriram sobre as forças da natureza um tal controle que, com sua ajuda, não teriam dificuldades em se exterminarem uns aos outros, até o último homem. Sabem disso e é dai que provém grande parte de sua atual inquietação, de sua infelicidade e de sua angústia.}

\section{Pacto social, pulsão de morte e violência}

Com a construção do mito da horda primeva, Freud (1913) afirma a função do terceiro, já evidenciada em sua maior fonte de dados - a prática clínica. Assim, ele ergue o que para a psicanálise vem a se constituir em sua ética: o campo do desejo. A lei da proibição do incesto e do assassinato - pilares da história freudiana fica mais bem postulada como Lei do desamparo entendida como uma ética da Lei que, quando não opera pela intermediação de um terceiro, faz preponderar a onipotência e, em conseqüência, seus possíveis efeitos psíquicos e sociais, podendo culminar na morte orgânica e na não-sustentação da vida psíquica. O que afirmamos é a necessária operação da castração e o modo como ela incide instaurando o limite, o outro como limite ao narcisismo e o amor pelo outro.

A teoria das pulsões aflora, então, a ética de que fala a psicanálise, ou melhor, a ética que constitui a psicanálise. Nas palavras de Birman (1994, p. 153):

\section{é na ética que o sujeito se singulariza em face de uma lei universal, de maneira que é no registro da ética que se pode delinear um lugar possivel para o sujeito, onde este seja marcado pela imposição da lei moral universalizante como exigência de existir numa comunidade de iguais, mas indicando ao mesmo tempo como o sujeito é único no campo transcendente do universal.}

Totem e Tabu (1913), nesse sentido, pode ser mais bem lido através das noções de aliança, troca, violência, dívida, culpa, compromisso, promessa... A consideração desses conceitos facilita a apreensão daquilo que surge como mais interessante na ficção freudiana. Como se sabe, Freud lançou a hipótese de que o homem primitivo vivia em uma horda original, no seio da qual o pai possuía o poder e as mulheres, mantendo seus filhos à parte. Impulsionados pelo ódio, os filhos se reúnem e matam o pai, decidindo que nenhum deles teria o poder, já que se dão conta de que tal posição deslancharia uma querela mortífera entre eles.

A relação entre os irmãos se impõe como necessária para o estabelecimento de qualquer possibilidade de constituição de projetos comuns pela prática dolorosa da renúncia pulsional. Entretanto, tal empresa coletiva não supõe, muito pelo contrário, a abolição da culpa, da inveja e do ciúme, bem como também do sofrimento relativo à condição original de desamparo.

Freud fala em mal-estar (1930) e não em aniquilamento - o que só seria pensável pelo exercício da pulsão de morte pura -, permitindo-nos possibilidades plurais de existência psíquica e social. Por nos situarmos no campo do conflito entre amor e ódio, nossa existência se situa na luta entre essas duas forças pulsionais. Entre os efeitos dessa articulação convém salientar que a pulsão de morte não aparece como o início e o final, como parênteses que encerram a vida. Ela faz parte de seu movimento vital, envolvendo-o na luta que trava perenemente com Eros, sendo mais preponderante em alguns momentos e atividades. Sempre em conflito, como forças do mesmo aparato psíquico que se constituem, tais pulsões compartilham do mesmo estofo originário gerando mal-estar e tensão.

Bom exemplo dessa complicação é que o desejo puro aponta para o gozo destruidor, mortífero. Embora Freud conceba as pulsões entrançadas e cruzadas, ele não as equipara, pois esse confronto não faz do mal-estar uma fatalidade em que os sujeitos estão afogados sem possibilidade de escape: é a aposta em Eros que prevalece, que faz cultura, que lança o sujeito nesta malha que é o existir psíquico. É pelo seu trabalho de ligação que a pulsão de morte se inscreve, inscrevendo o sujeito diante do seu desamparo fundamental.

Como já é sabido, a maior parte dos estudos em psicanálise enfoca o estado atual de exacerbação da violência como decorrente da falência da Lei do Pai, o que levaria a uma fragilidade suprema no pacto social, à não-legitimidade das leis culturais decorrentes da desestruturação dos vínculos e ao usufruto gozoso dos bens culturais, primordialmente, pela desconsideração da noção de outro.

Ressaltamos que a função paterna não constitui argumento exclusivo para a explicação da organização coletiva, fazendo-se necessária a consideração da fraternidade entre os irmãos. A morte do Pai funda a Lei, o pacto entre os irmãos no pacto social. São os filhos que instauram a Lei, pois a lei do pai era a lei do gozo. Abordar essas noções, bem como as de outro e 
outro nos situa no campo da ética e é nele que o sujeito se defronta com a ordem de filiação. A ética, enfatizamos, diz respeito ao desejo e ao sentido da vida que decorre dele. Ela significa inscrever-se na sociedade e ter seus benefícios, inclusive a possibilidade de erotização do corpo e das relações intersubjetivas. Espera-se que uma sociedade limite os riscos para os sujeitos que fazem parte dela, porém que ela deixe espaços para as experiências singulares e para os riscos delas decorrentes. Nesse sentido, o lugar ético diz respeito à acolhida de um sujeito pela rede social, acolhida que não pode se resumir ao seu caráter repressivo. As leis, portanto, não devem estar presentes só para punir, mas para impor questões sobre como viver juntos e como é possível se constituir e se manter uma sociedade humana.

\section{Considerações finais}

A problemática da violência e de seus destinos contemporâneos, alastrados por todos os segmentos subjetivos e sociais, faz-nos pensar no estatuto da pulsão de morte na contemporaneidade. Zafiropoulos (1994, p. 9) escreve que o solo epistemológico das pesquisas freudianas é caracterizado pela consideração do "trabalho silencioso" no social. Toda a proposta freudiana de construção do sujeito supõe esse exercício de ambivalência entre Eros e Tanatos. O que permite vinculação entre as duas forças pulsionais seria $O$ Nome-do-Pai, para trabalharmos com o esclarecedor conceito lacaniano.

A perenidade da pulsão de morte e de sua atividade no aparelho psíquico constitui um dos pólos do dualismo na constituição do sujeito, mesmo que agindo em silêncio. $O$ silêncio pode ser rompido quando tal pulsão orienta-se contra o eu ou se dirige contra o mundo exterior com toda sua potência de agressão e destruição do objeto.

Em uma conjuntura pulsional na qual a pulsão de morte opera abertamente, o pacto com a vida é rompido pela atuação da violência destrutiva em suas formas extremas. A ação específica e solitária da pulsão de morte, pela desintricação pulsional, pode se dar pela desobjetalização, exprimindo-se em sua amplitude máxima de destruição. Os objetos são esvaziados em sua qualidade de outro, de semelhante. Seguindo tal raciocínio, Tanatos pode atingir níveis arriscados quando o laço social se enfraquece pelo afastamento de Eros.

A época em que vivemos denuncia uma urgência em construirmos metáforas que atribuam sentido às nossas vivências subjetivas e sociais. As reflexões sobre os vínculos fraternais impõem-se com urgência e constituem espaço de vida perpassado por questões éticas com base nas quais teríamos que nos perguntar que metáforas nos são possíveis ou mesmo por que caminhos podemos remetaforizar os lugares subjetivos que ocupamos.

O lugar da fratria e todas as conseqüências advindas do confronto das subjetividades merecem ser dimensionados pela complexidade da existência coletiva. A soberania do Pai pode ser interrogada e revista metapsicologicamente a partir de os filhos assumirem as responsabilidades e compromissos com o social. Sugerimos que quando o acento recai no momento lógico no qual os filhos impõem-se como cúmplices e construtores das normas sociais, talvez possamos vislumbrar possibilidades outras de sociabilidade.

Não propomos uma transposição explicativa da constituição do sujeito e do social somente pela alternância da ênfase da função paterna para a fratria, já que correríamos o risco de cair nas mesmas armadilhas conceituais pelas quais todos os fatos sociais adversos à realização subjetiva e à existência do social são explicados, quase que linearmente, pela nãooperatividade do Nome-do-Pai.

Sublinhar os elos que fazem os sujeitos membros de uma fratria como proposta de modelo social parece confrontar-nos com problemas de outra ordem, como, por exemplo, os que caracterizam as relações horizontais de adolescentes pertencentes a um grupo. Entretanto, pensamos que essa mudança do enfoque vertical Pai-filhos para uma postura teórica que o ilumine juntamente com a horizontalidade instaurada pelos irmãos possa ser útil em seus aspectos metapsicológicos e clínicos.

\section{Referências}

Assoun, P. L. (1993). Freud et les sciences sociales Psychanalyse et théorie de la Culture. Paris: Armand Colin.

Birman, J. (1994). Psicanálise, Ciência e Cultura. Rio de Janeiro: Jorge Zahar.

Freud, S. (1980). A sexualidade na etiologia das neuroses (1898). Em Edição Standard das Obras Psicológicas Completas de Sigmund Freud. Rio de Janeiro: Imago, v. III.

Freud, S. (1980). Os Três ensaios para uma Teoria da Sexualidade (1905). Em Edição Standard das Obras Psicológicas Completas de Sigmund Freud. Rio de Janeiro: Imago, v. VII. 
Freud, S. (1980). Comportamentos obsessivos e práticas religiosas (1907). Em Edição Standard das Obras Psicológicas Completas de Sigmund Freud. Rio de Janeiro: Imago, v. IX.

Freud, S. (1980). Moral sexual civilizada e doença nervosa moderna (1908). Em Edição Standard das Obras Psicológicas Completas de Sigmund Freud. Rio de Janeiro: Imago, v. IX.

Freud, S. (1980). Notas sobre um caso de neurose obsessiva (1909). Em Edição Standard das Obras Psicológicas Completas de Sigmund Freud. Rio de Janeiro: Imago, v. X.

Freud, S. (1980). Uma recordação de infância de Leonardo da Vinci (1910). Em Edição Standard das Obras Psicológicas Completas de Sigmund Freud. Rio de Janeiro: Imago, v. XI.

Freud, S. (1980). Totem e tabu (1913 [1912-13]). Em Edição Standard das Obras Psicológicas Completas de Sigmund Freud. Rio de Janeiro: Imago, v. XIII.

Freud, S. (1980). O Moisés de Michelangelo (1914). Em Edição Standard das Obras Psicológicas Completas de Sigmund Freud. Rio de Janeiro: Imago, v. XIII.

Freud, S. (1980). Psicologia das massas e análise do eu (1921). Em Edição Standard das Obras Psicológicas Completas de Sigmund Freud. Rio de Janeiro: Imago, v. XVIII.

Freud, S. (1980). O futuro de uma ilusão (1927). Em Edição Standard das Obras Psicológicas Completas de
Sigmund Freud. Rio de Janeiro: Imago, v. XXI.

Freud, S. (1980). O mal-estar na civilização (1930). Em Edição Standard das Obras Psicológicas Completas de Sigmund Freud. Rio de Janeiro: Imago, v. XXI.

Freud, S. (1980). Por que a guerra? (1933[1932]). Em Edição Standard das Obras Psicológicas Completas de Sigmund Freud. Rio de Janeiro: Imago, v. XXII.

Freud, S. (1980). Moisés e o monoteísmo: três ensaios (1939 [1934-38]). Em Edição Standard das Obras Psicológicas Completas de Sigmund Freud. Rio de Janeiro: Imago, v. XXIII.

Jerusalinsky, A. (1996). Somos todos violentos? Revista da APPOA. Psicanálise em Tempos de Violência, VI (12). Porto Alegre: Artes e Ofícios, 7-14.

Kaufmann, P. (1974). Psychanalyse et theorie de la culture. Paris, Denoël/Gonthier.

Mezan, R. (1990). Freud, pensador da cultura. São Paulo: Brasiliense.

Zafiropoulos, M. (1994). Présentation. Em: Assoun, P.-L. \& Zafiropoulos, M. (Orgs.). La règle sociale et son audèla inconscient. Psychanalyse et pratiques sociales. Paris: Anthropos.

Recebido em 04/02/2002

Revisado em 24/07/2002 Aceito em 21/10/2002

Sobre a autora:

Leônia Cavalcante Teixeira é doutora em Saúde Coletiva pelo Instituto de Medicina Social-UERJ, mestre em Educação pela UFC, psicóloga, psicanalista e professora do mestrado e da graduação em Psicologia da Universidade de Fortaleza. Atualmente, a professora realiza pesquisas sobre psicopatologias somáticas, tendo como áreas de interesse: psicanálise e cultura, literatura e subjetividade, práticas de saúde e saberes psicológicos. 